\title{
Geodetic Monitoring of the Surface within the Trial Operation of the Room and Pillar Mining Method in the Ostrava-Karvina Coal District
}

\author{
Eva Jiránková1 ${ }^{*}$, Jitka Mučková1, Petr Jadviščok ${ }^{1}$, Robert Vochta², Vlastimil Molčák ${ }^{1}$, \\ Martina Havlicová ${ }^{1}$ \\ ${ }^{1}$ VŠB-Technical University, Ostrava, Czech Republic \\ ${ }^{2}$ Survey and Geology Manager, OKD, A.S., Mine Plant 2, Stonava, Czech Republic \\ Email: *eva.jirankova@vsb.cz
}

Received 1 December 2015; accepted 6 May 2016; published 9 May 2016

Copyright (C) 2016 by authors and Scientific Research Publishing Inc.

This work is licensed under the Creative Commons Attribution International License (CC BY).

http://creativecommons.org/licenses/by/4.0/

c) (i) Open Access

\begin{abstract}
Mine Plant 2 is a part of the Ostrava-Karvina Coal District (OKD) that is located in the Czech part of the Upper Silesian Basin. The first coal was exhausted from Mine Plant 2 in 1968. The most used method of mining so far in this area has been strike longwall mining with controlled caving. Due to extensive changes in the surface, which occur as a consequence of deep mining by the method of longwall mining with controlled caving, it is not possible to use this method in densely populated areas. At the present time, therefore, the trial operation of a new mining method called room and pillar is carried out. The method was chosen with the aim to minimize subsidence and deformations of the surface. The room and pillar mining method has never been used before in the conditions of the OKR, therefore it is necessary to prove the real effect of mining by this method on the surface. For this purpose, a surface observation station was designed, consisting of 36 surface points. The position and height of all points of the observation station is determined in stages three times a year.
\end{abstract}

\section{Keywords}

Surface Subsidence, Room and Pillar, Protective Pillar of the Shaft

\footnotetext{
${ }^{*}$ Corresponding author.
} 


\section{Introduction}

Due to deep mining, movements and deformations of the surface occur. Even though the extraction of coal deposits involves the remedy of damages incurred and the reclamation of the surrounding landscape, changes in the surface caused by mining are essential and irreversible.

The essential factor that limits mining activity is the degree to which the objects concerned are affected by it on the surface, i.e. the magnitude of movements and deformations of surface objects. With respect to the relatively demanding legislation that regulates consent to mining, the extension of a mining area in a densely populated area is very difficult. One of the solutions of the conflict of interest of the mining company and the owners of real estate is to find a suitable alternative method of mining, which will prove the least effect on the surface. For this purpose, the trial operation of the new room and pillar mining method was commenced. The task of the trial operation is to prove the usability of this method of mining in the conditions of deep bituminous coal mines of the Ostrava-Karvina Coal District. The principle of this method of mining is to leave stable pillars of coal that will be the permanent support of the roof, thus avoiding the layering of the roof, and the manifestation of mining on the surface will be minimal [1]-[4]. Geodetic monitoring of the surface is carried out simultaneously with geo-mechanical monitoring of coal pillars left in place. Within geo-mechanical monitoring, deformometry of the overlying rocks of tunnels is carried out, as well as monitoring and measurement of the stress state in the rock mass in the conditions in situ, deformometry of coal pillars, loading of installed anchor elements, measurement of the convergence of tunnels and seismological monitoring [5].

This paper is concerned with geodetic measurements, the purpose of which is the collection of data required for the evaluation of surface subsidence that will occur as a result of the effect of the room and pillar mining method. The trial operation of this new, not yet approved mining method for coal mining in the area of the OKR is carried out in the protective pillar of the shafts Sever (North) of Mining Plant 2. The tunnels of the stope are $5.2 \mathrm{~m}$ wide and $3.5 \mathrm{~m}$ high on average. The extent of the stope using the room and pillar method for the year 2014 is graphically depicted in Figure 1.

\section{Description of the Site}

From the mining-technical point of view, the selected area is not quite ideal for the trial operation of the new mining method. Equally as in the other parts of the coal district, the rock mass is relatively much tectonically fractured there, with the layers dipping up to 20 degrees and the depth of mining being 750 to 900 metres below the ground surface.

In the protective pillar of the shafts Sever, there is a downcast and an upcast shaft (Figure 1). Deformations of the shafts are measured once a year; the methods of measurement are still being developed [6]. Even though it is the first mining in the protective pillar of the shafts Sever, this area suffers subsidence of the surface being about $15 \mathrm{~mm}$ a year; the to talsubsidence from the beginning of mining activity is about $630 \mathrm{~mm}$. Therefore, it is necessary to gather a required amount of geodetic data so that it can be possible to prove in the future, what part of the value of surface subsidence the effect of mining using the room and pillar method is accounted for, under the current effect of longwall mining with controlled caving of coal faces at the efficient distance from the protective pillar of the shafts Sever [7]-[10].

For the purposes of geodetic measurements, an observation station was stabilized on the surface, consisting of three aligning bases and surface points in a reclaimed area along the state road 475 and the bridge construction of a floating pipeline. The stabilization of surface points was carried out in a manner corresponding to the technical requirements for the stabilization of points of the vertical point network. In all, twenty seven new surface points were stabilized; the observation station also includes points stabilized earlier—six points of the base point network of Mine Plant 2 and three points earlier stabilized by the workers of Mine Plant 2 to measure surface movements.

Surface line no. 1 is formed by ten surface points situated in the premises of Mine Plant 2 Sever. Surface line no. 2 is formed by nine surface points situated along the access road to Mine Plant 2 Sever around the crossroads with the state road no. 475 . Surface line no. 3 is formed by ten surface points stabilized in the road shoulder of a closed road running along a railroad siding of Advanced World Transport a.s. The observation station also includes seven surface points stabilized in a reclaimed area-two points were stabilized along the road 475 and five points were stabilized into the abutments of the bridge construction of the floating pipeline. The position of all points of the observation station is graphically depicted in Figure 1 and Figure 2. 


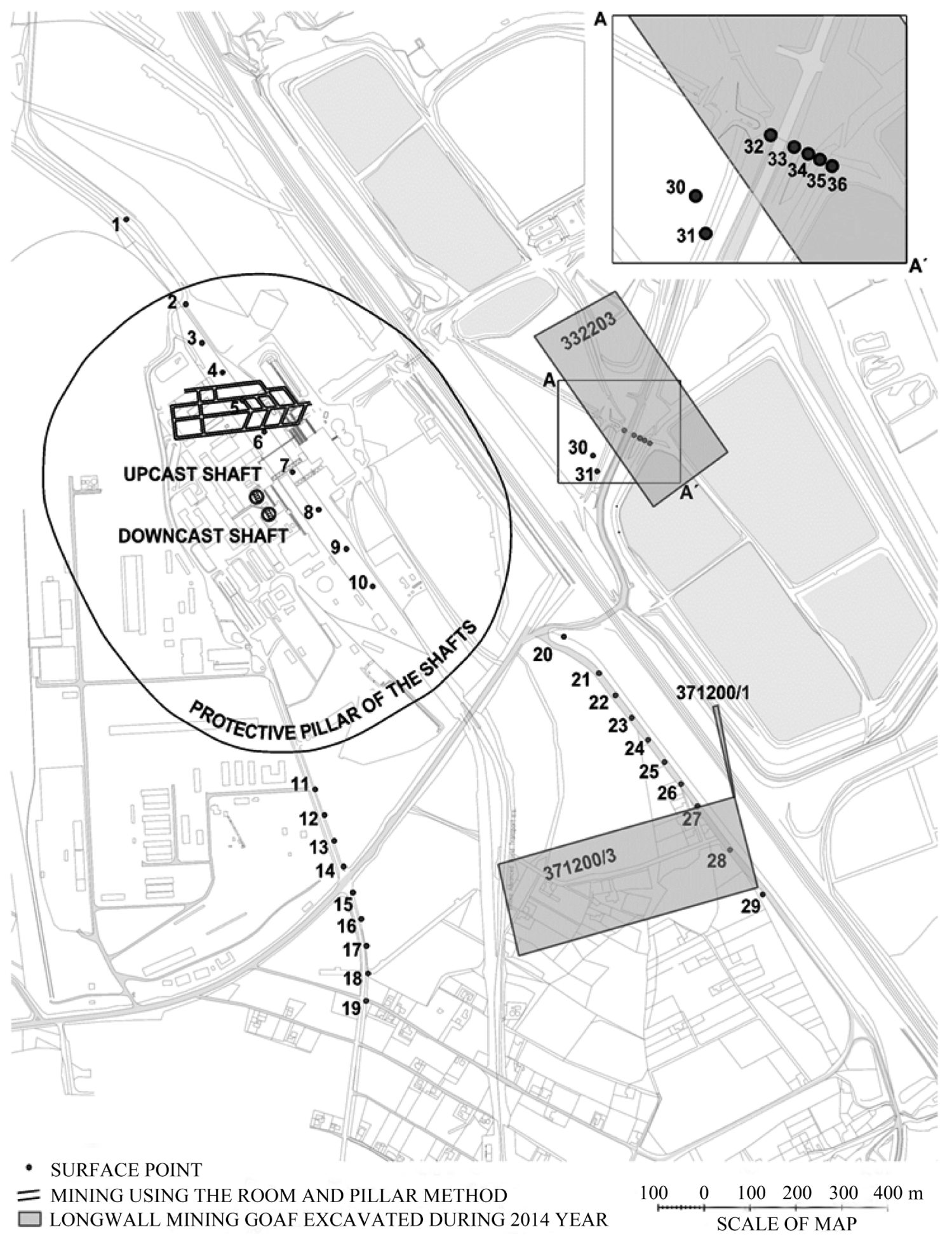

Figure 1. Surface pointsof aligning bases and the extent of mining for the year 2014 .

\section{The Method of Measurement}

In all, three stages of geodetic measurements of the height and position of surface points were carried out in 2014. The first measurement was made on 2 April 2014, the second one on 29 July 2014 and the third one on 7 November 2014. 


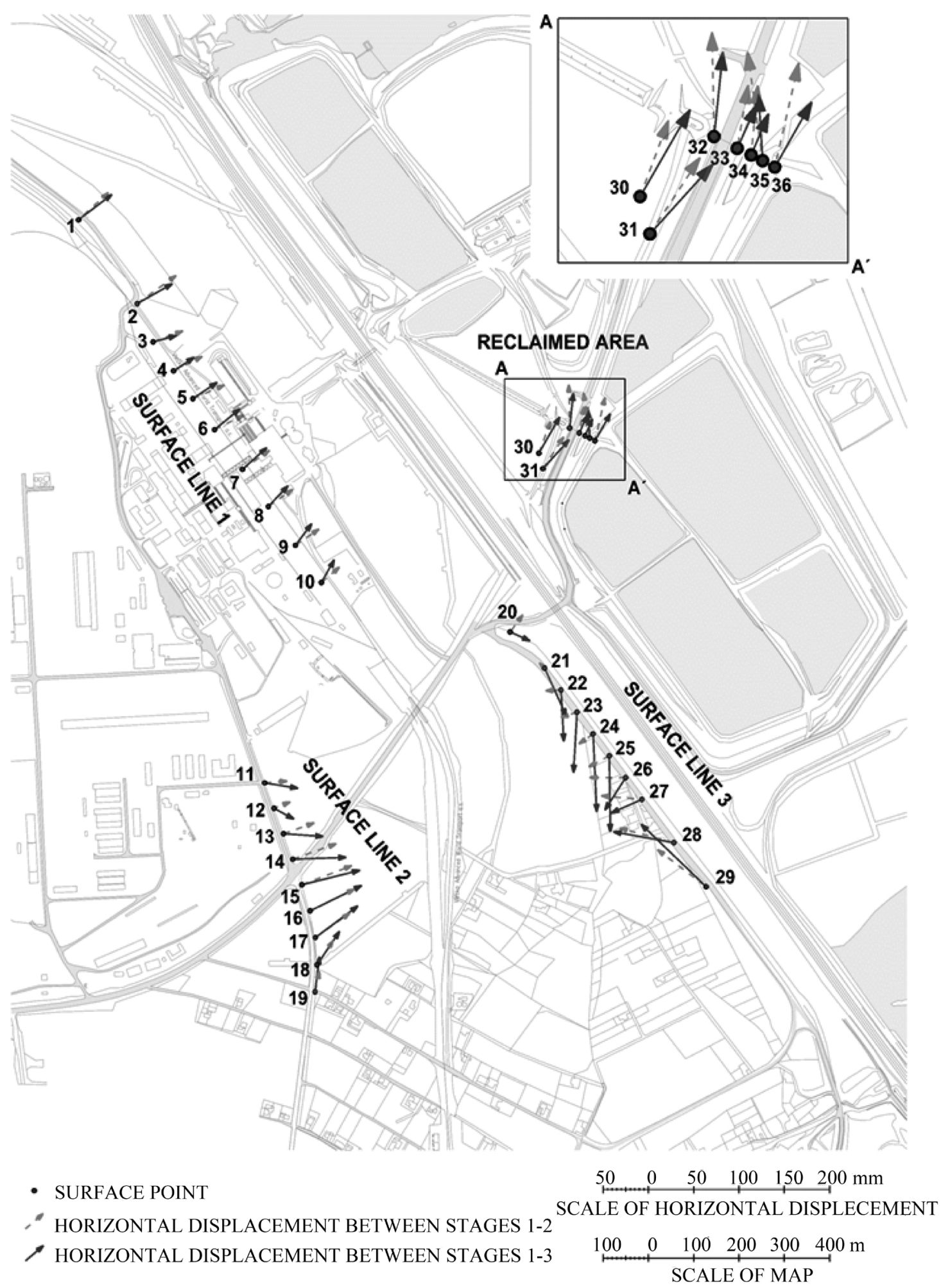

Figure 2. Graphical depiction of horizontal displacements of surface points.

The measurement of the heights of surface points was carried out using geometric levelling from the centre between the staffs in the category of precise measurements. A teach stage of measurement, the points of the observation station were vertically connected from a non-undermined area. The measurements were carried out 
using an electronic levelling instrument DNA 03 Leica with invar staffs 3 metres long. The mean kilometre error given by the manufacturer of this instrument is $0.3 \mathrm{~mm}$. The length of the levelling line, including connection from the non-undermined area, is $8.1 \mathrm{~km}$.

The heights of points of the linear observation station were determined from two independent measurements. For each stage of measurement, the characteristics of accuracy were calculated; the mean kilometre error of the first stage of measurement carried out on 2 April 2014 is $1.8 \mathrm{~mm}$, the mean kilometre error of the second stage of measurement carried out on 29 July 2014 is $1.3 \mathrm{~mm}$ and the mean kilometre error of the third stage of measurement carried out on 7 November 2014 is $1.7 \mathrm{~mm}$.

The measurement of the position of surface points was carried out on aligning bases using traverses oriented and connected on both sides. The accuracy of the measurement of traverses was in the category of precise measurements. For precise measurement, an instrument TCR 1201 Leica with accessories was used. The parameters of accuracy given by the manufacturer of this instrument are $1 \mathrm{~mm}$ for length measurement with a prismatic reflection system, $0.3 \mathrm{mg}$ on for measuring horizontal angles in one position of the telescope and 0.3 $\mathrm{mg}$ on as well for measuring vertical angles. Connection to S-JTSK was carried out using the points of the end sides of traverses, which were surveyed by the GNSS method. The position of all seven surface points stabilized in the reclaimed area was also measured by the GNSS method.

Of the GNSS methods, a rapid static method was used, with the time of observance being approximately 20 minutes at one point. At each point it was necessary to measure at least one repeated independent measurement. An independent measurement is considered to be a new surveying of the position of points by the same method with the lapse of time of at least 1 hour. The accuracy of this method depends on instantaneous atmospheric conditions and disturbing effects of the environment, if any. The accuracy of this method ranges in values of the order of around $3 \mathrm{~mm}$ in the position of the determined point. Measurement was carried out using an instrument RX1250XC Leica with an antenna ATX 1230 and accessories.

\section{The Results of Measurement}

The results of vertical and horizontal measurement were used to determine subsidence and displacements of surface points. Subsidence is the vertical component of the spatial movement of the surface point and is determined as the difference between the heights of the same point over a certain period of time. The mean error of subsidence was calculated as the root of the quadratic sum of mean kilometre errors determined from the individual stages of measurement. Displacement is the horizontal component of the spatial movement of the surface point and is determined over a certain period of time from the difference of the position of the point measured at the beginning and at the end of the period of time. The vector of displacement is governed by its magnitude and the bearing in S-JTSK. The mean error of horizontal displacements was calculated as the root of the quadratic sum of the mean horizontal errors determined from the individual stages of measurement.

Subsidence and displacements determined by the values exceeding the confidential interval are designated as proved with an appropriate risk. The confidential interval with a 5\% risk was determined as the double the mean error of subsidence and displacements. Both the subsidence and the displacements of aligning bases 2 and 3 and the points of the reclaimed area were with the $5 \%$ risk; only displacements with the $5 \%$ risk were proved for the surface points of aligning base 1. A graphical depiction of subsidence is given in Figures 3-6 and displacements are shown in Figure 2.

\section{Interpretation of the Results}

The surface observation station was stabilized and surveyed at the beginning of mining in the protective pillar of the shafts using the room and pillar method. An uplift of the points of aligning base 1, with the values ranging from 1.9 to $3.2 \mathrm{~mm}$, has been identified from the second measurement of heights of surface points (Figure 3). The results of the third measurement of heights show evident subsidence of surface points of aligning base 1 as compared to the second stage, yet points 1 to 7 show uplift, as compared to the first stage of measurement. In relation to the length of the traverse connected to the non-undermined area, it was not possible to prove these low values of uplifts by the method of measurement. Subsidence of the surface points of aligning bases 2 and 3 and the surface points stabilized in the reclaimed area has been proved by the method of measurement and their values correspond to the intensity and extent of strike longwall mining with controlled caving (Figures 4-6).

The protective pillar of the shafts is constructed using the pillar angle, which is steeper relative to the critical 


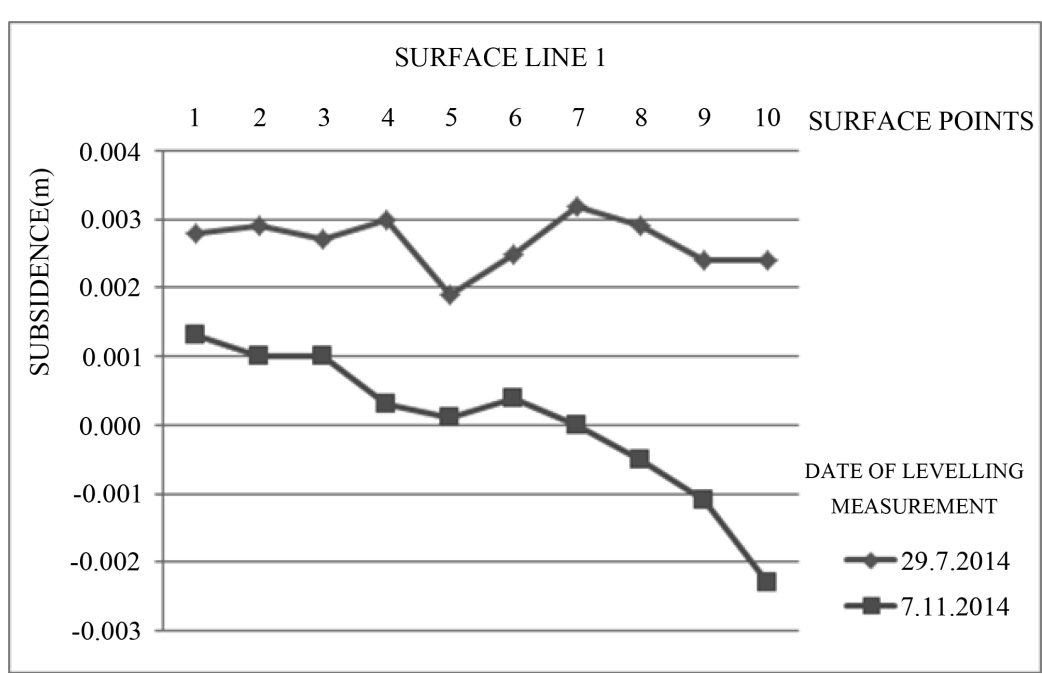

Figure 3. Graphical depiction of subsidence of surface points of aligning base 1 .

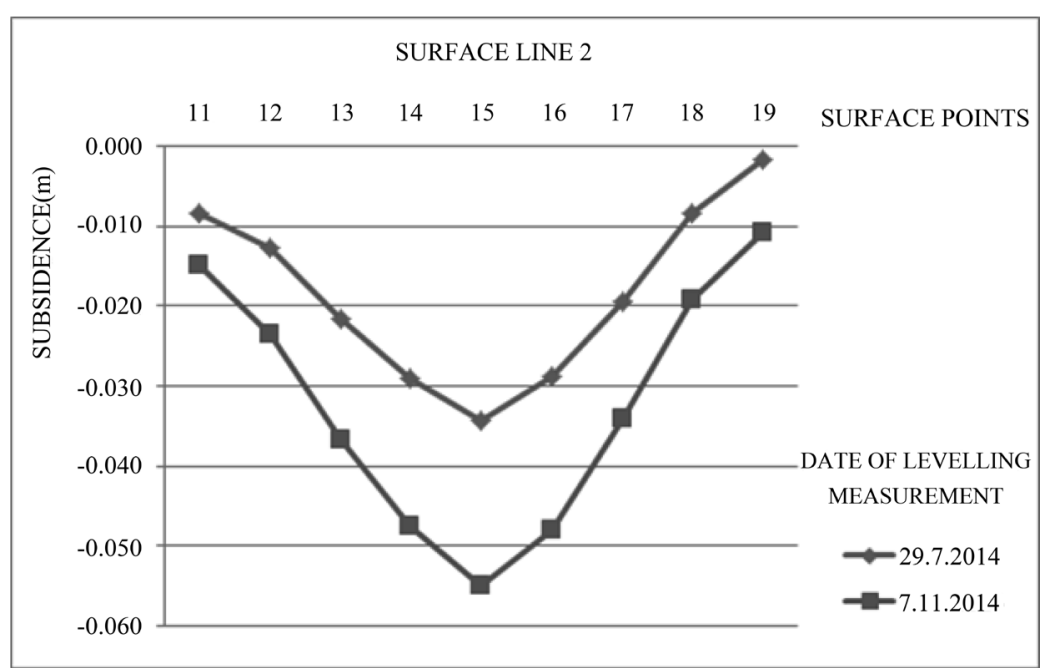

Figure 4. Graphical depiction of subsidence of surface points of aligning base 2.

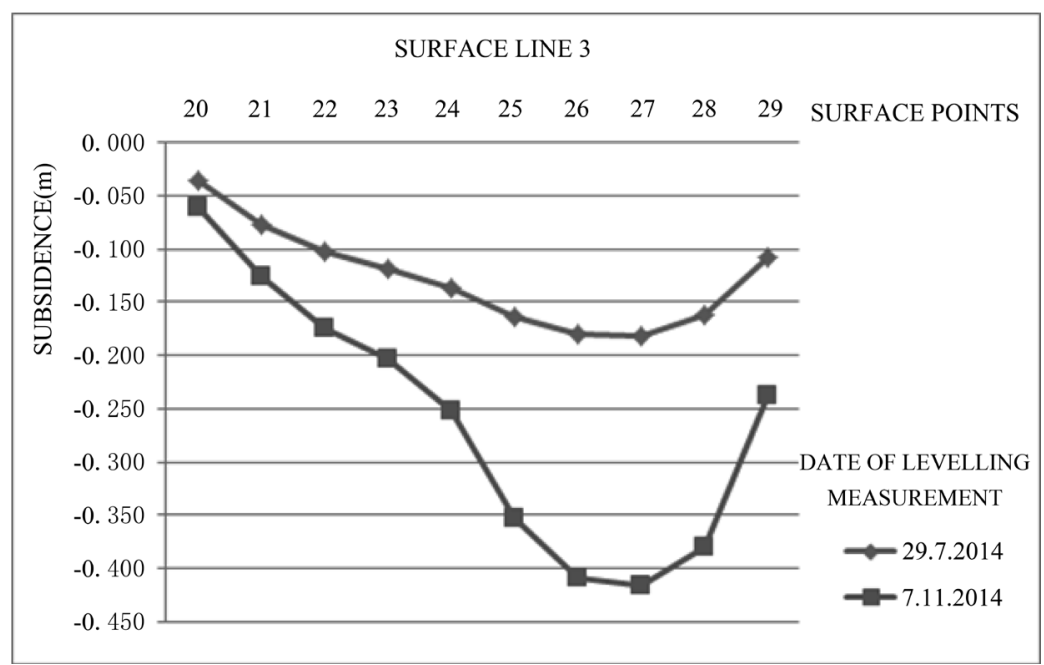

Figure 5. Graphical depiction of subsidence of surfacepoints of aligning base 3 . 


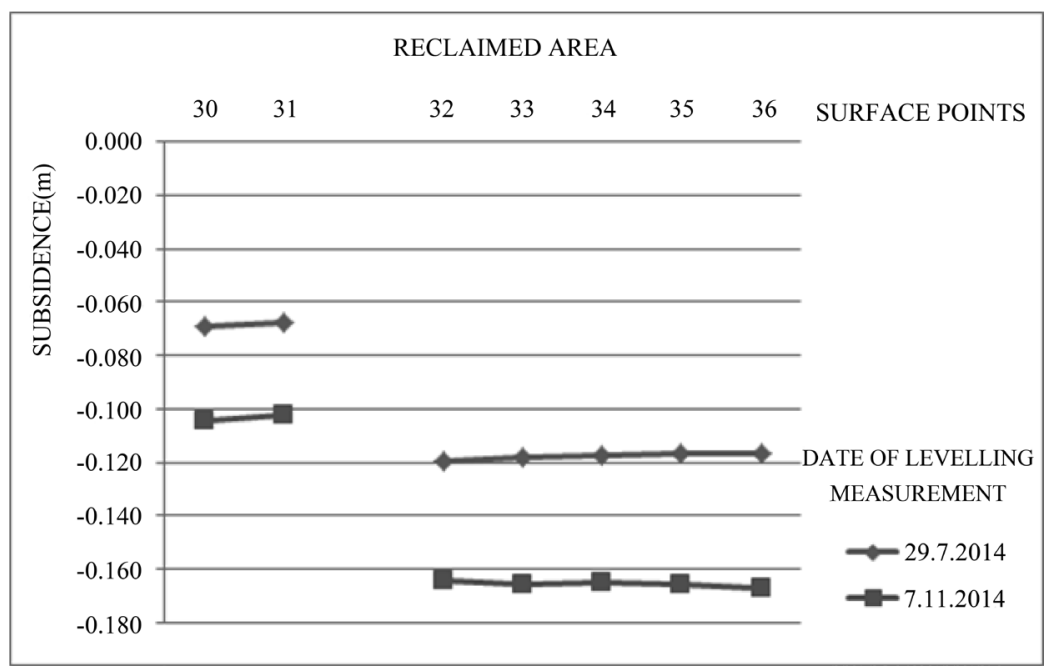

Figure 6. Graphical depiction of subsidence of surface points stabilized in thereclaimed area.

angle of influence. Therefore, the effect of surrounding mining is partially manifested in the protective pillar of the shafts. The surface in the area of the protective pillar is thus affected both by surrounding mining and by mining in the protective pillar using the room and pillar method. In order to separate the effect of room and pillar mining from the overall effect of mining on the surface in the area of the protective pillar, it was necessary to design the surface observation station so that it could be possible to evaluate also the effect of mining that takes place at the effective distance from the protective pillar. At the same time, it was necessary to measure not only the subsidence of surface points, but the whole vector of movement, i.e. also the horizontal displacement. Based on the results of measurement, a refined theoretical model of subsidence troughs formed around the protective pillar can be developed and the effect of surrounding mining on the surface in the area of the protective pillar can be determined. Then it will be possible to separate the effect of the room and pillar mining method itself on the surface.

The results obtained clearly show that in the first year of trial operation of the new mining method, the body of the protective pillar was drawn towards the centre of gravity of the stope of active strike longwall mining with controlled caving in coal seam 33 (Figure 2). The stope in coal seam 33 includes coal face 332,203, which is located at the effective distance from the protective pillar and was mined during the first year of trial operation. This fact is shown by the directions of the vectors of displacements of surface points of aligning base 1 and surface points stabilized in the reclaimed area, which generally aim towards the centre of gravity of the stope. Another active strike longwall mining with controlled caving takes place in coal seam 37 . The stope in coal seam 37 also includes coal face $371,200 / 3$, which was mined during the first year of trial operation of the new mining method. The vectors of displacements of surface points of aligning bases 2 and 3 generally aim towards the centre of gravity of the stope in coal seam 37 (Figure 2). Based on these findings it can be presumed that a subsidence trough is being formed above the stope in coal seam 37 at the time of mining coal face $371200 / 3$, the slope of which has a minimum effect on the movement of surface points of aligning base 1 and thus also on the area of the surface of the protective pillar of the shafts.

\section{Conclusions}

The room and pillar method of mining has never been used in the Ostrava-Karvina Coal District. The aim of trial operation is to prove the possibility of using the technology of room and pillar mining in the conditions of the OKR and to achieve consent of the State Mining Administration to the implementation of the new mining method on the basis of results. A great asset would then be the use of this method of mining in heavily developed areas.

The purpose of geodetic measurement is to collect data required for the evaluation of surface subsidence that will occur as a consequence of the effect of the room and pillar mining method in the protective pillar of the shafts Sever of the Mine Plant 2. With respect to the expected values of movements of surface points, the 
method of measurement of both the position and the height of the observed points was chosen in the category of precise measurements. The objective of geodetic measurements is to prove the real effect of the room and pillar mining method on the surface.

\section{References}

[1] Peng, S.S. (2008) Coal Mine Ground Control. 3rd Edition, Department of Mining Engineering/College of Engineering and Mineral Resources, Morgantown, $750 \mathrm{p}$.

[2] Feng, Q.B. (2008) Numerical Simulation of Coal Pillar Stability in Room-Pillar Mining. Coal Mining Technology, 6, 10 .

[3] Yang, J.X., Liu, C.Y., Yang, Y. and Li, J.W. (2013) Study of the Bearing Mechanism of the Coal Roof and the Dimension Selection of the Room and Pillar in the Shallow and Close Distance Coal Seam. Journal of China University of Mining and Technology, 2, 161-168.

[4] Ghasemi, E., Ataei, M., Shahriar, K., Sereshki, F., Jalali, S.E. and Ramazanzadeh, A. (2012) Assessment of Roof Fall Risk during Retreat Mining in Room and Pillar Coal Mines. International Journal of Rock Mechanics and Mining Sciences, 54, 80-89.

[5] Waclawik, P., Ptacek, J., Konicek, P., Kukutsch, R. and Nemcik, J. (2015) Stress-State Monitoring of Coal Pillars during Room and Pillar Extraction. Gornicze Zagrozenia Naturalne, Targanice, 3-5 November 2015.

[6] Černota, P., Staňková, H., Gašinec, J. and Labant, S. (2014) New Method of Swing Observation to Determine Accurate Plummet Position at the Plumb Line for Both Connecting Surveys and Orientation Measurements. Acta Montanistica Slovaca, 19, 221-227.

[7] Sheorey, P.R., et al. (2000) Ground Subsidence Observations and a Modified Influence Function Method for Complete Subsidence Prediction. International Journal of Rock Mechanics and Mining Sciences, 37, 801-818. http://dx.doi.org/10.1016/S1365-1609(00)00023-X

[8] Jiránková, E. (2012) Utilisation of Surface Subsidence Measurements in Assessing Failures of Rigid Strata Overlying Extracted Coal Seams. International Journal of Rock Mechanics and Mining Sciences, 53, 111-119. http://dx.doi.org/10.1016/j.ijrmms.2012.05.007

[9] Reddish, D.J. and Whittaker, B.N. (2012) Subsidence: Occurrence, Prediction and Control. Elsevier.

[10] Woo, K.S., Eberhardt, E., Elmo, D. and Stead, D. (2013) Empirical Investigation and Characterization of Surface Subsidence Related to Block Cave Mining. International Journal of Rock Mechanics and Mining Sciences, 61, 31-42. http://dx.doi.org/10.1016/j.ijrmms.2013.01.015 